\title{
Fertile grounds for the growth of biotechnology
}

THE Carlsberg Brewery in Copenhagen is a sprawling industrial estate at the centre of which is a heavy redstone entrance to what had been the original plant, now cocooned as a kind of museum. Modern Carlsberg is spread across the world in more than 40 countries, the more so since Carlsberg swallowed, a decade ago,

Tuborg, Denmark's other big beer. But the brewery, an early manifestation of biotechnology, is now doing a great deal to return the benefits it has derived over centuries from science.

The Carlsberg Foundation is not simply a shareholder in the brewery but is also a research organization in its own right. Like other research foundations with roots in a science-based company, the foundation makes grants for good works - scientific meetings, Danish researchers' travels abroad and so on. But now it is also directly engaged in basic re-

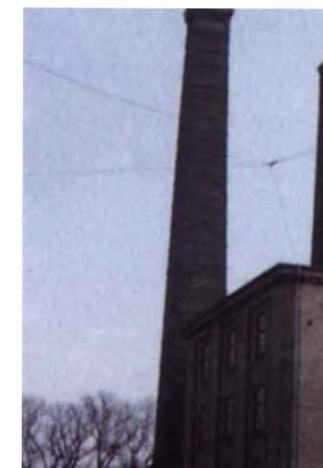

place, relationships with the works laboratory are strong and getting stronger.

Klaus Bock, head of the chemistry division at the Carlsberg Foundation laboratory, explains that the requirement that his research programme should have something to do with the basic science of brewing is, these days, not an irksome restriction. For one thing, most organic

Definitely Carlsberg's oldest brewery ...
For the past ten years, the bulk of the foundation's research has indeed been biotechnology. Bock reckons that the Carlsberg Foundation has done as much as most other organizations to introduce these novel techniques to Denmark as well as to stimulate the government's own interest in an earmarked biotechnology programme.

But that, Bock says, does not mean that the foundation's interests will be swamped by work stimulated elsewhere. The foundation's research park continues to take in students (from universities all over Denmark). It is also a productive centre of postdoctoral fellowships and has sufficiently deep pockets to attract people away from other posts when it feels it needs them.

But why does Denmark so emphasize biotechnology? Bock has a simple answer. Apart from brewing, the traditional industries,

search on the brewery site. And because it seems to the pragmatic men in charge to make no sense to have two scientific organizations with similar ownership and objectives working separately in the same

ques (and even the software) used for the analysis of data are familiar in a dozen laboratories worldwide. The calculation is that successful management of the European Communities contract will enable the laboratory at Aarhus to rub shoulders with the others in the field. This is how to bootstrap your way to international status - but with the proviso that you must succeed with the contract that may give you that right.

Both the physicists and the biologists of the medical faculty agree about the general problems of doing science competitively in small countries. Surprisingly (for this is almost unprecedented talk), everybody agrees that there is no real shortage of funds for travel. Faculty members can attend meetings they need to without much difficulty and the small amount of bureaucracy with which they must contend is probably just that needed to ensure that they do not attend peripheral meetings as well. But even grants for postdoctoral fellowships and the departmental graduate education ensure that unestablished people are also able to travel. One need of small-country science is evidently that its public sponsors should recognize the need for physical processes resemble the transformations of the brewing process in one way or another. But yeasts, in any case, are useful model organisms for all kinds of studies.

\section{movement.}

The people at Aarhus also congratulate themselves that, unlike many in the United States, for example, they are not required to compete for funds for technical assistance. The university budget allows for a hard core of technical staff to be kept on the university books and to become the kind of technicians who are able to contribute as much to the development of technique as do researchers themselves.

But not every department in a university such as Aarhus can realistically hope to be up with the best. Indeed, one of the crucial problems of countries such as Denmark (mirrored it appears in the other Nordic countries) is the way in which essentially open access by students forces the need for a faculty which is itself comprehensive - one in which many teaching loads will be less equal than others. It is agreed that only discrimination in the allotment of resources between one department and another will allow this task to be done well.

The dean of science at Aarhus, Professor Carl Petersen, says openly (even in the presence of his dependent heads of department) that even a large university mostly turning milk into cheese, made people worry about germs even before Pasteur introduced the term. Now, the techniques of fermenting and maturing hygienically are in the Danish blood.

in a small country cannot succeed unless somebody has the authority to make clear decisions.

So much will be assured by the new University Law, now making its way through the complicated consultative procedures of the Danish parliament. In retrospect, it seems agreed that the legislation of the early 1970s formally went too far to invest power and authority in students and nonteaching staff. The new arrangements will take back some of those concessions but also require the universities to reorganize their teaching the better to suit the needs of their students. Under the same legislation, the heads of research institutes, deans and rectors will have more power than before.

Formally, that means that the capacity to make clear decisions should be confirmed. It also, at Aarhus, seems to mean that most departments will take the chance to put graduate courses on a more formal basis than at present, partly replacing the standard research project with more formal teaching. Some regret that prospect. Others, like Carl Petersen, say "there's no other way of getting the throughput we need". 